\title{
Practical Considerations When Prescribing Icodextrin: A Narrative Review
}

\author{
Samuel A. Silver Ziv Harel Jeffrey Perl \\ Division of Nephrology, St. Michael's Hospital, University of Toronto, Toronto, Ont., Canada
}

\section{Key Words}

Adverse reactions $\cdot$ Hypoglycemia $\cdot$ Icodextrin $\cdot$ Maltose $\cdot$

Patient safety $\cdot$ Peritoneal dialysis

\begin{abstract}
Background: Icodextrin is a peritoneal dialysis solution that is commonly used to increase ultrafiltration during the long dwell. The other major clinical benefit of icodextrin is that it is glucose-sparing, which may help preserve peritoneal membrane function. Since it has a different chemical composition than dextrose, and with its increasing use, there are several clinical considerations healthcare providers must familiarize themselves with prior to prescribing icodextrin. Summary: Failure to recognize these special properties of icodextrin can lead to adverse events reaching patients. This narrative review explores the hemodynamic, metabolic, and idiopathic effects of icodextrin to facilitate the safe use of icodextrin in peritoneal dialysis. Key Messages: Hemodynamic effects include hypotension from enhanced ultrafiltration contributing to loss of residual kidney function. Metabolic effects include the chemical structure of icodextrin interfering with biochemical assays, resulting in misleading glucose readings on non-specific glucometers. Idiopathic adverse effects include a diffuse rash and sterile peritonitis. It is also important to remember that not all antibiotic combinations have undergone stability testing in icodextrin. This narrative review will help healthcare providers to confidently prescribe icodextrin to maximize its benefit in peritoneal dialysis patients.

(c) 2014 S. Karger AG, Basel
\end{abstract}

(C) 2014 S. Karger AG Basel

0250-8095/14/0396-0515\$39.50/0

\section{Introduction}

Twenty years since the introduction of icodextrin in the United Kingdom in 1994, its use continues to expand to over 30,000 patients worldwide in more than 55 countries [1]. In the developed world, its penetration exceeds $50 \%$ [2]. This is despite increased costs associated with icodextrin compared to dextrose-based solutions.

Its success stems from its unique chemical properties that affect ultrafiltration (UF) and clearance. Icodextrin is a glucose polymer with a molecular weight of $16,800 \mathrm{Da}$ resulting in a sustained colloid osmotic gradient. It is absorbed from the peritoneal cavity mainly via the lymphatic circulation, and the amount absorbed ranges from 20 to $40 \%$ for an $8-16 \mathrm{~h}$ dwell $[3,4]$. Absorption also occurs at a slower rate than dextrose-based peritoneal dialysis (PD) solutions. Therefore, icodextrin can achieve a greater net UF during the long dwell compared with conventional dextrose-based PD solutions.

Icodextrin solute and fluid transport relies predominantly on the small pore system, while hypertonic dialysate (such as dextrose) relies on both the small pores and the water-selective aquaporin-1 pores [5]. This has two effects: (1) the initial fall in dialysate sodium concentration, known as sodium sieving, does not occur with icodextrin and (2) the high flow across the small pores with icodextrin enhances convective transport of small and middle molecules [6]. This has practical implications, as switching from dextrose to icodextrin in the overnight

\section{KARGER}

E-Mail karger@karger.com

www.karger.com/ajn
Dr. Samuel Silver

Division of Nephrology, St. Michael's Hospital

University of Toronto, 3-060 Shuter Wing

30 Bond Street, Toronto, ON M5B 1W8 (Canada)

E-Mail sam.silver@utoronto.ca 
Table 1. Established and potential clinical benefits of icodextrin

- Increased ultrafiltration, particularly in high transporters $[7,8]$

- Improved glycemic control in diabetic patients $[10,11]$

- Improved lipid profiles $[10,11]$

- Improvements in left ventricular geometry $[12,13]$

- Enhanced phosphate removal [14]

- ? Preserved peritoneal membrane function [16]

- ? Increased technique survival $[18,19]$

exchange among continuous ambulatory peritoneal dialysis (CAPD) patients may reduce morning thirst via elimination of sodium sieving.

Icodextrin has a number of clinical benefits (table 1). Two meta-analyses have demonstrated the superiority of icodextrin in maximizing UF during the long dwells of both CAPD and automated peritoneal dialysis (APD) patients compared with dextrose-based solutions [7, 8]. Bioelectrical impedance analysis suggests a positive correlation between improved fluid balance and blood pressure with estimates of total body water, extracellular water, and extra/intracellular water ratio [9]. However, no significant differences were observed in the meta-analyses with respect to mortality, peritonitis, or total adverse events.

In diabetic patients, icodextrin offers a glucose-sparing option that may improve glycemic control and other metabolic parameters. Several trials have demonstrated improvements in traditional lipid markers (total cholesterol, LDL, HDL, triglycerides) and novel lipid markers (apolipoprotein B) $[10,11]$. Icodextrin may also have favorable effects on left ventricular geometry. Echocardiographic parameters have been shown to improve with icodextrin, with a $13 \mathrm{~g}$ difference in left ventricular mass in one study and a reduction in left ventricular end diastolic diameter in another study $[12,13]$. One study also demonstrated enhanced phosphate removal with icodextrin, which ameliorated cardiac hypertrophy and vascular calcification [14].

Effects of inflammation and technique survival with icodextrin are mixed. Systemic C-reactive protein levels vary by study as being increased or decreased $[15,16]$, but markers of intraperitoneal inflammation (IL-6, TNF- $\alpha$, fibrinogen degradation products) appear to increase with icodextrin [17]. The long-term implications of these findings on clinical outcomes and peritoneal membrane structure and function are unclear. While data on technique failure was lacking in the meta-analyses described above, one recent trial and Korean registry study suggest that icodextrin may increase technique survival rates $[18$,
19]. More data will be needed to confirm these encouraging preliminary findings.

Icodextrin has many clinical benefits that explain its growth and popularity in PD programs worldwide. Maximizing the clinical benefits of icodextrin requires an indepth understanding of all clinical consequences regarding its use. In the present review, we will highlight prescriptive considerations and emphasize practical clinical consequences when using icodextrin to ensure that it enhances the health of PD patients, while minimizing and avoiding unintentional harm.

\section{Hemodynamic Effects}

\section{Ultrafiltration and Blood Pressure}

With the enhanced UF provided by icodextrin, patients may be at risk for hypovolemia and even hypotension. While this pattern has been observed in several clinical trials, the effect on blood pressure remains mixed (fig. 1).

A multicenter randomized double-blind trial compared icodextrin to $4.25 \%$ dextrose in 92 patients on APD that had high-average to high peritoneal transport characteristics [20]. During the 2-week study period, net UF was unchanged from baseline in the dextrose group but increased significantly in the icodextrin group. The incidence of negative net UF was also significantly lower in the icodextrin group $(\mathrm{p}<0.0001)$. In this 2 -week trial, blood pressure was relatively well controlled in both groups at baseline and throughout the study.

Trials of longer duration have found a greater impact of icodextrin use on blood pressure control. A multicenter randomized double-blind trial comparing icodextrin with $2.27 \%$ dextrose in 50 hypertensive patients with urine output $<750 \mathrm{ml} /$ day found the icodextrin group lost weight and achieved better UF than the dextrose group [21]. This effect was apparent within the first month of the trial and was sustained for 6 months. Despite the enhanced UF, this study found no significant differences in the mean and median 24-hour blood pressure readings between the treatment groups at any time point. However, there was a signal that patients in the icodextrin group required more adjustments to their antihypertensive regimens. In this regard, patients randomized to icodextrin were more likely to reduce their hypertensive medication (33\%) compared with the dextrose group (14\%).

A 12-month multicenter open-label randomized trial compared icodextrin $(n=30)$ to dextrose $(n=29)$ long dwells in diabetic CAPD patients with high-average and 


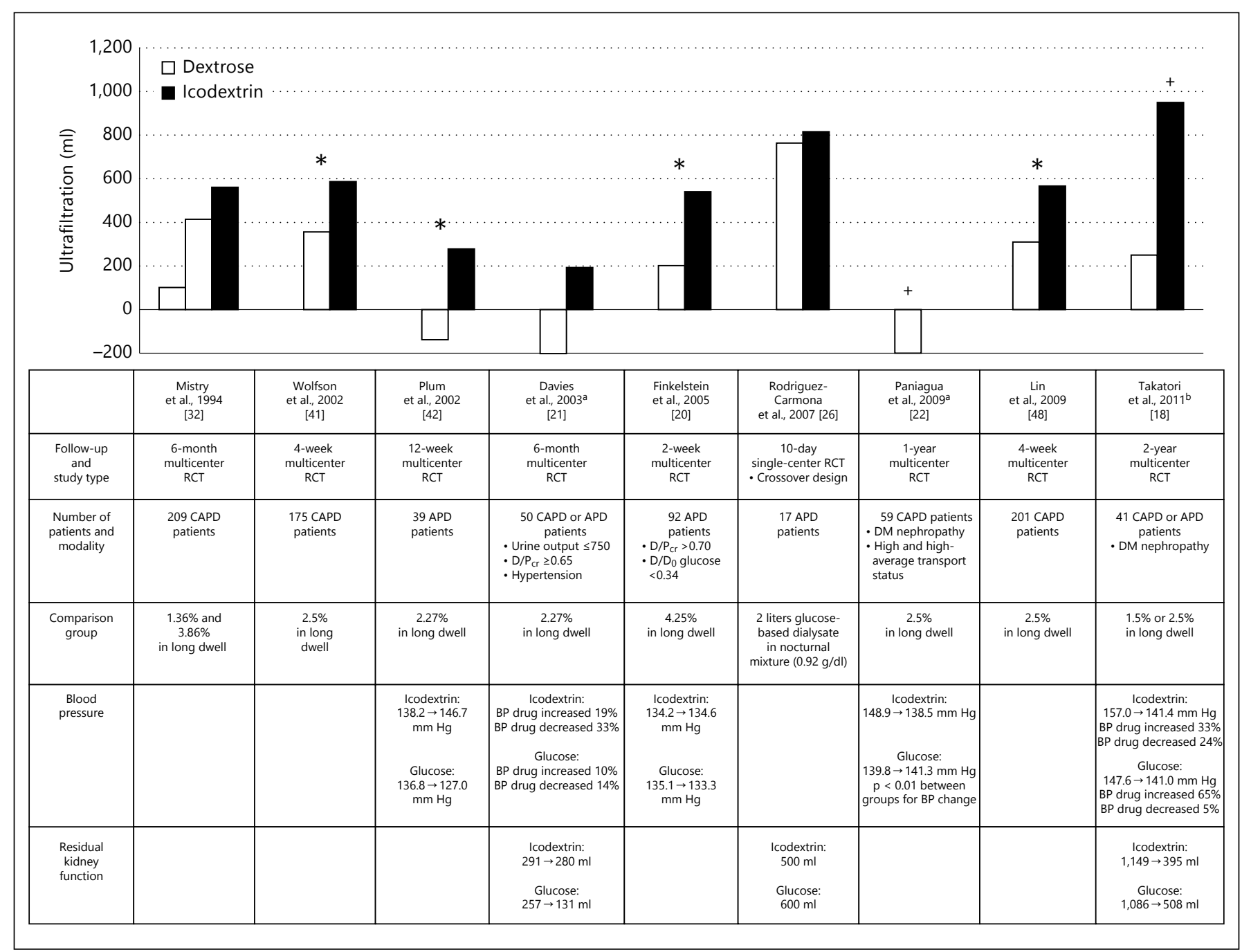

Fig. 1. Selected studies of the impact of icodextrin on UF, blood pressure (BP), and RKF. White shading corresponds to dextrose $\mathrm{PD}$ solutions, and black shading corresponds to icodextrin. $\mathrm{DM}=$
Diabetes mellitus; RCT $=$ randomized controlled trial. ${ }^{a} \mathrm{UF}$ amount compared to baseline (absolute UF not provided); ${ }^{\mathrm{b}}$ UF estimated from study tables (absolute UF not provided). ${ }^{*} \mathrm{p}<0.001 ;{ }^{+} \mathrm{p}<0.05$. high peritoneal transport characteristics [12, 22]. Similar to the previous trials, UF was improved in the icodextrin group. Within the first 6 months, reduction in ambulatory blood pressure and left ventricular end-diastolic diameter were found in the icodextrin group.

A more recent randomized open-label trial enrolled 41 incident PD patients with diabetic nephropathy and assigned them to either an icodextrin or dextrose long dwell [18]. The technique survival rate was $71.4 \%$ in the icodextrin group and $45.0 \%$ in the dextrose group, with most of the technique failure due to volume overload. Net UF was significantly higher in the icodextrin group throughout the 2-year study period. Blood pressure was also better

Considerations When Prescribing Icodextrin controlled in the icodextrin group, dropping from 157.0 to $141.4 \mathrm{~mm} \mathrm{Hg}$. Dosages of antihypertensive agents were increased in $33 \%$ of icodextrin and $65 \%$ of dextrose patients, whereas they were reduced in $24 \%$ of icodextrin and $5 \%$ of dextrose patients.

All the trials above are of limited power. However, enhanced UF is a consistent trend amongst all the studies (fig. 1). In daily practice, some patients may be an exception, which is thought to be secondary to high lymphatic absorption of icodextrin and its metabolites negating the osmotic gradient that drives UF [23]. Alternatively, when icodextrin is initiated early in the course of PD therapy, impaired UF may be a manifestation of mechanical com- 
plications, such as catheter and non-catheter-related dialysate leaks. These complications are more common among patients new to PD and patients who used to be empty during the day. In summary, patients presenting with UF failure on icodextrin should undergo a complete work-up into all possible etiologies [23].

In the majority of patients with enhanced UF on icodextrin, the lack of consistency in improved UF on blood pressure control is on the surface disappointing and differs from the findings of previous observational studies $[9,24]$. However, it should be noted that in many of the controlled trials, achieved blood pressure in both icodextrin and dextrose groups was excellent, likely reflecting diligent care by participating investigators. Moreover, drained body weight also did not change in many of the studies. This suggests that PD patients may compensate for the increased UF with icodextrin by a simultaneous increase in fluid intake. This may limit the ability to detect true blood pressure improvements without controlling for any impact on body volume composition. In the few studies in which investigators coupled enhanced UF with dietary restrictions, improved blood pressure control has been observed with the use of icodextrin $[9,25]$.

Our local practice is to wait until peritoneal membrane characteristics have stabilized (typically occurs 4-6 weeks after PD initiation) before starting icodextrin in incident PD patients. This allows us to initiate icodextrin after completion of the first peritoneal equilibration test in an effort to better understand the expected UF based on the availability of membrane characteristics and UF capacity. Moreover, we monitor UF closely to ensure that hypotension does not develop. In particularly frail and vulnerable patients or patients in whom the prescription was adjusted to address adequacy instead of UF, icodextrin may be prescribed incrementally starting with either lower dwell volumes $(<1$ liter) or administered on alternating days until the patient response to the enhanced UF is better appreciated. We also avoid the addition of new antihypertensive medications or hypertonic glucose-based solutions, if possible. These strategies have helped our program encounter few episodes of hypotension upon icodextrin initiation.

\section{Loss of Residual Kidney Function}

An additional concern with the enhanced UF achieved with icodextrin is that volume depletion will lead to a decrease in residual urine volume. This finding has been noted in a number of observational studies, but the results have been mixed in randomized controlled trials (fig. 1).
Davies et al. [21] found that residual kidney function (RKF) was preserved and superior to the conventional dextrose solution at 6 months. Despite enhanced UF and lower weight, the icodextrin group had better maintenance of urine volume at 6 months that approached statistical significance.

A randomized crossover single-center study examined 17 APD patients by substituting 2 liters of dextrose-based dialysate with a similar volume of icodextrin solution in the nocturnal mixture [26]. In this study, the icodextrin schedule was associated with marginal yet statistically significant reduction in RKF compared with the dextroseonly schedule. The major limitation of this study is that it only followed patients on icodextrin for a 10-day period. Therefore, the small loss in RKF could simply represent an immediate negative reaction to the modest increase in UF under this regimen.

Takatori et al. [18] pre-specified RKF as a secondary outcome in their 2-year study of 41 patients. Over the study period, urine volumes progressively decreased to $395 \mathrm{ml} /$ day in the icodextrin group and $508 \mathrm{ml} /$ day in the dextrose group. No statistical difference between the two groups was observed, although both groups demonstrated a significant decline at 24 months in comparison to the respective baseline values. These results suggest that the use of icodextrin sustained RKF for 2 years at a rate comparable to dextrose-based dialysis solutions.

The effect of icodextrin on RKF is particularly difficult to study, since the natural course in PD patients is for RKF to decline over time regardless of the PD solution used. Also, any peritoneal membrane UF changes will influence RKF. Study results range from a modest increase in RKF to a slight decrease in RKF. The fact that no drastic declines in RKF have been described is reassuring, but the lack of evidence at this point in time suggests that RKF should be monitored at regular intervals in patients that begin an icodextrin regimen. During periods in which patients may be particularly susceptible to RKF decline (i.e. radiocontrast procedures), our practice has been to hold icodextrin transiently as part of a strategy to mitigate the risk of extracellular fluid volume contraction. Overall, there is currently insufficient evidence to recommend stopping an icodextrin PD regimen based solely upon declining RKF.

\section{Metabolic Considerations}

\section{Maltose Accumulation}

Even though only a fraction of the icodextrin glucose polymer load is absorbed, the metabolism of icodextrin is 


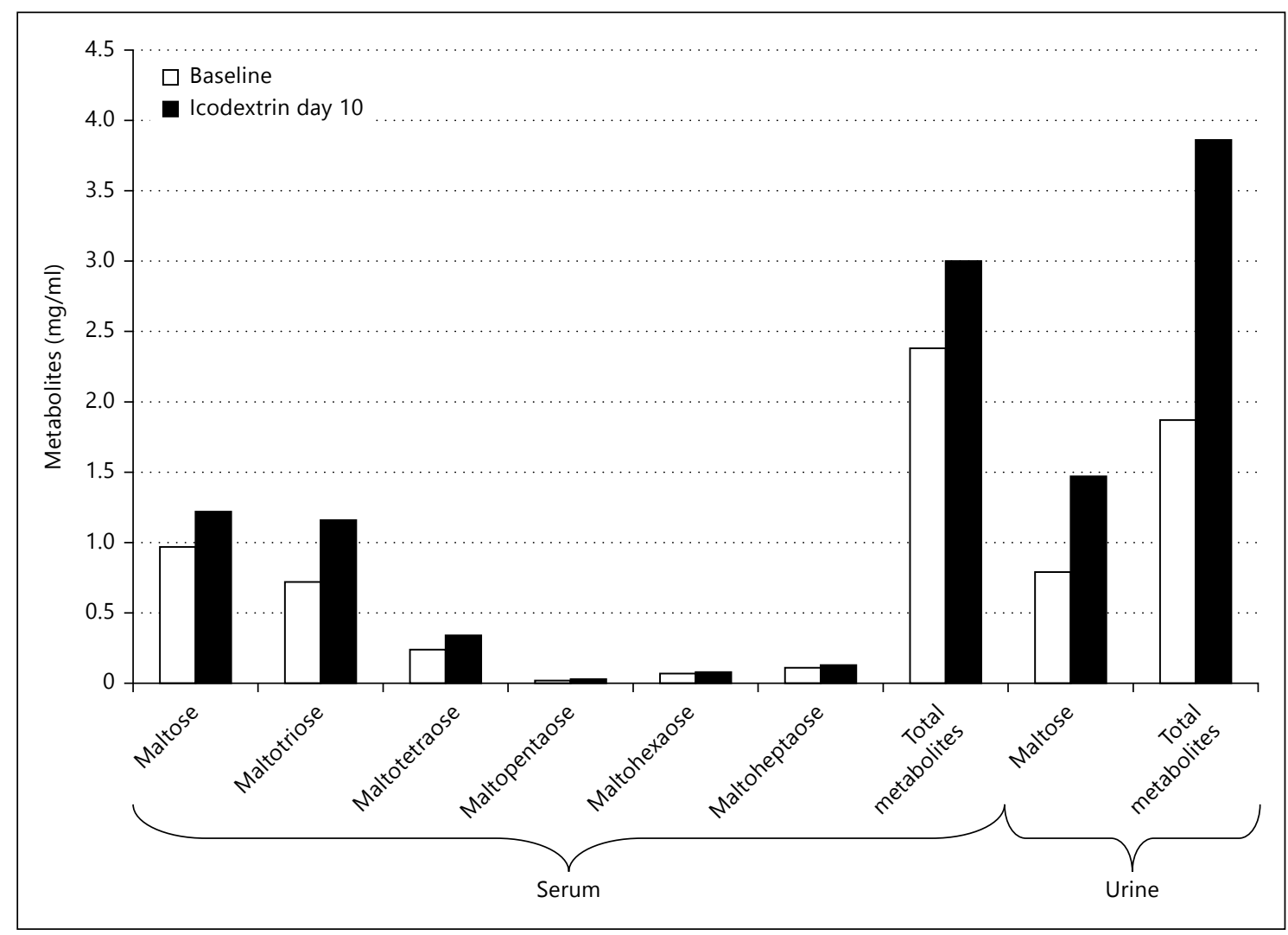

Fig. 2. Serum and urine levels of icodextrin metabolites (in $\mathrm{mg} / \mathrm{ml}$ ). White shading corresponds to metabolite levels at baseline, and black shading corresponds to levels on day 10 of icodextrin therapy. $\mathrm{p}<0.05$ for all metabolites except maltopentaose. Adapted from Rodriguez-Carmona et al. [26].

incomplete. The absorbed polymer is rapidly hydrolyzed by amylase to oligosaccharides and eventually to maltose. Further metabolism is limited by the absence of maltase activity in the human circulation [27]. There has been concern expressed regarding possible tissue accumulation of dextran [28] and hydroxyethyl starch [29], and it is possible that this may occur with icodextrin. In contrast to polysaccharides such as dextran and hydroxyethyl starch, icodextrin is a highly soluble product readily metabolized by intra- and extracellular amylase and maltase [30].

The short-term 20-day crossover study by RodriguezCarmona et al. [26] measured serum and urinary concentrations of icodextrin metabolites by filtration chromatography [31]. Serum and urine levels of icodextrin metabolites showed predictable behavior, increasing significantly during the icodextrin phase (fig. 2). Longterm implications and safety of exposure to this level of icodextrin metabolites was not addressed by this study.

The MIDAS trial [32] was a multicenter randomized controlled trial of 209 CAPD patients that compared overnight icodextrin to overnight dextrose exchanges over a 6-month period. Serum samples for estimation of icodextrin and oligosaccharides were obtained immediately prior to the study and at 1,3 , and 6 months. The mean level of icodextrin and its metabolites increased from a baseline value of $0.35 \mathrm{~g} / \mathrm{l}$ to a steady-state level of $4.87 \mathrm{~g} / \mathrm{l}$. The serum maltose followed an identical pattern and rose from $0.04 \mathrm{~g} / \mathrm{l}$ to a steady-state level of $1.20 \mathrm{~g} / \mathrm{l}$. This increase occurred within 2 weeks of icodextrin administration, and steady-state levels were maintained throughout the 6-month study duration. These metabolites were not associated with any adverse clinical effects.

In patients who received icodextrin for more than 2 years, a small group was further studied to investigate the effect on icodextrin and maltose metabolite levels upon cessation of icodextrin treatment [33]. The levels fell to pre-treatment values within 2 weeks. Upon recommencing icodextrin after a 3-week period of non-use, the icodextrin and maltose metabolite levels rose to the initial treatment phase and reached a plateau within 2 weeks. 
The authors argue that these icodextrin kinetics suggest that there can be no capacity-Iimited compartment for icodextrin metabolites. Therefore, deposition of icodextrin in tissues is unlikely.

This is reassuring data for novel therapies that may lead to icodextrin exposure beyond a single exchange per day. One option entails prescribing two icodextrin bags during a 24-hour period. This can be done with or without continued dextrose-based cycler therapy at night [34]. A second novel therapy involves bimodal solutions, where dextrose and icodextrin agents are combined into a single solution to limit glucose exposure while enhancing UF and sodium loss [35]. A randomized trial comparing a bimodal solution to icodextrin alone is currently recruiting (clinicaltrials.gov: NCT01242904). Despite the promise of double icodextrin exchanges and bimodal solutions in initial studies, these therapies should not be adopted into routine practice until more data is available regarding long-term outcomes.

\section{Insulin Requirements and Hypoglycemia}

Clinicians must keep in mind that insulin requirements may decrease when substituting an icodextrin for a dextrose-based dwell. Dextrose-based PD regimens typically result in a daily absorption of 150-300 g of glucose, and the caloric load from an icodextrin exchange is less than a $2.5 \%$ dextrose exchange [36]. Small and non-randomized trials have demonstrated mixed results on the effect of icodextrin on glycemic control. Three long-term randomized controlled trials specified glucose metabolism as primary or secondary outcomes. Paniagua et al. [22] found that patients in the icodextrin group had better metabolic control than those in the dextrose group with lower insulin requirements ( -9.1 vs. +3.6 units/day, $\mathrm{p}<0.01)$, fasting serum glucose $(-37$ vs. $+8.3 \mathrm{mg} / \mathrm{dl}$, $\mathrm{p}<$ $0.01)$, and $\mathrm{HbA}_{1 \mathrm{c}}(-0.98$ vs. $+0.79 \%, \mathrm{p}<0.01)$. Takatori et al. [18] found that $\mathrm{HbA}_{1 \mathrm{c}}$ was significantly higher in the glucose group than in icodextrin group at 12 and 18 months. However, at the end of the 2-year study, no statistical difference was observed between the two groups (glucose $6.0 \%$, icodextrin $5.5 \%$ ).

The IMPENDIA-EDEN open-label trial combined two studies and randomized 127 patients to dextrose-only and 124 patients to a dextrose, icodextrin, and amino acid solution for 6 months [10]. The primary outcome was a change in $\mathrm{HbA}_{1 \mathrm{c}}$ from baseline. They found that the $\mathrm{HbA}_{1 \mathrm{c}}$ improved in the intervention group but remained unchanged in the control group $(0.5 \%$ difference between groups, $\mathrm{p}=0.006$ ). The separation between treatment groups was observed as early as 3 months. A post hoc analysis showed no decrease in insulin use by treatment group. 15 hypoglycemic events (4 serious) developed in the treatment group, compared with 4 (0 serious) in the control group. The icodextrin group also experienced a higher number of serious adverse events (105 vs. 78 events) and deaths (11 vs. 5 deaths). Many of these events were due to congestive heart failure and hypertension, which was surprising given the improved UF with icodextrin described previously. The authors hypothesize that some centers may have used lower concentrations of dextrose in the intervention group to target glycemic control, at the expense of lower UF and volume overload.

Based on these three studies, there is insufficient data to support proactive reductions in insulin requirements for patients started on icodextrin. However, we would recommend that all diabetic patients be advised to monitor more closely for hypoglycemia upon initiation of icodextrin.

The method used to monitor blood sugar while on icodextrin is important. Non-glucose sugars (such as icodextrin metabolites) are measured by many diabetes devices/ strips as 'glucose,' resulting in falsely elevated readings. Most devices use non-specific test strip methods that utilize glucose dehydrogenase pyrroloquinoline quinone or glucose dehydrogenase flavin-adenine dinucleotide, and so are unable to distinguish glucose from non-glucose sugars, such as maltose [37].

This creates a situation where inappropriate excessive insulin may be administered by healthcare professionals who mistakenly interpret the glucometer device findings as hyperglycemia. This can result in patients experiencing hypoglycemia, neurologic damage, coma, or even death. From 1997 to 2009, the United States Food and Drug Administration (FDA) received 13 reports of death due to non-specific test strips with documentation of interference from maltose and other non-glucose sugars. Of these 13 patients, 10 were on PD using icodextrin [38]. The scope of this patient safety issue is large, as glucometers and glucose test strips are ubiquitous in healthcare environments; they are used in every emergency center, outpatient care facility, intensive care unit, and hospital nursing unit.

The period when icodextrin is discontinued is another sensitive period for PD patients. Since maltose metabolites with icodextrin do not return to baseline until 2 weeks after cessation, non-glucose-specific monitors and test strips place $\mathrm{PD}$ patients at risk of iatrogenic hypoglycemia for weeks after their last exposure to icodextrin [39]. Even the most diligent clinician may fail to obtain a relevant prior history of icodextrin exposure within this window 
of time. Therefore, vigilance is required on the part of both healthcare providers, patients, and their families.

A recent article from Baxter Healthcare's pharmacovigilance database between the dates of 2010-2012 describes 3 cases of iatrogenic hypoglycemia in PD patients. A common thread to these cases is that the patients were cared for by non-renal services, usually around the time of an operation. Of the 3 cases, 2 ended up in the ICU for severe hypoglycemia [38]. Baxter Healthcare has established a risk management program that includes electronic web-based safety tools (www.glucosesafety.com) [39]. A list of all devices and test strip products that are glucose-specific, and those that are not, is available on this website. This resource is available in 75 countries and 37 languages. Baxter Healthcare has also supplied wallet cards, wearable necklaces and bracelets, and hospital admission kits to better communicate the risk of hypoglycemia with icodextrin [39].

Therefore, hospitals and healthcare providers that care for both PD patients and patients recently treated with PD (i.e. post kidney transplantation) must utilize caution when purchasing diabetes-monitoring devices and test strips. A policy mandating glucose-specific devices would be the safest strategy, but at the very least, warning stickers should be placed on all non-glucose-specific glucometers as a visual alert that these devices have limitations and should not be used in recent or current icodextrintreated PD patients.

\section{Amylase Interpretation}

In addition to interfering with the measurement of glucose, serum amylase activity is reduced with icodextrin, which can complicate the diagnosis of pancreatitis. Schoenicke et al. [40] evaluated serum samples from 22 stable patients on PD. Blood samples were drawn from 11 patients given a once-daily exchange with icodextrin for the long dwell and from 11 PD patients given only dextrose. Serum amylase activity was reduced by $90 \%$ in patients given icodextrin compared to patients given dextrose ( 15.9 vs. $157.1 \mathrm{U} / \mathrm{l}, \mathrm{p}<0.001)$. The authors speculate that amylase affinity for icodextrin may be higher than that of the labelled test oligosaccharide in the assay. Icodextrin is a $\beta$-glucose polymer consisting mainly of a1,4-linkages. Amylase breaks a1,4-linkages. Since most methods for determining amylase in routine clinical practice are based on the consumption of substrate, spuriously low concentrations of serum amylase may be measured. These data support the conclusion that icodextrin creates a competitive interaction with the amylase substrate.

Considerations When Prescribing Icodextrin
These observations have also been confirmed in clinical trials. A 52-week randomized double-blind study of 287 patients found a significant decline in serum amylase concentration in icodextrin-treated patients $(-87 \mathrm{U} / \mathrm{l})$ [41]. A second randomized trial of 39 patients included a 2 -week baseline period followed by a 12-week icodextrin treatment phase, and then a 2-week follow-up period when switching back to dextrose [42]. There was a marked decrease of serum $\alpha$-amylase activity in the patients using icodextrin $(\mathrm{p}<0.001)$. After 12 weeks of treatment, serum $\alpha$-amylase activity decreased from 103 to $16 \mathrm{U} / \mathrm{l}$ ( $\mathrm{p}<$ 0.001 ). Serum amylase activity returned to near baseline levels in the follow-up phase.

This evidence supports the need for caution when evaluating PD patients for pancreatitis. Amylase is not a useful test and lipase must be used instead.

\section{Alkaline Phosphatase}

A small increase in serum alkaline phosphatase (ALP) has been reported in some studies of icodextrin, including two randomized controlled trials $[41,42]$. The study by Plum et al. [42] included a 2 -week baseline period, followed by a 12 -week icodextrin treatment phase, and a 2-week follow-up period when switching back to dextrose. ALP levels increased significantly in the icodextrin group, but remained within normal limits. ALP levels returned to baseline with cessation of icodextrin, suggesting that elevations were neither permanent nor related to significant liver injury.

One proposed mechanism for the small increase in ALP during icodextrin treatment is a partial inhibition of ALP clearance due to competition between ALP and icodextrin for hepatocyte asialoglycoprotein receptors [36]. Increases in ALP with icodextrin have not been associated with any clinical symptoms or abnormalities in any other liver function tests.

\section{Hyponatremia}

Icodextrin solution clearly leads to accumulation of maltose in the extracellular volume. This gradient induces osmotic flow by a mechanism similar to isosmolar colloid osmosis [36]. The resultant shift in water from the intracellular to the extracellular space can result in a mild hyponatremia.

The MIDAS trial found that the biochemical profiles of its participants were no different in the two groups except for a small fall in serum sodium $(140 \rightarrow 136 \mathrm{mmol} / \mathrm{l})$ and chloride $(103 \rightarrow 99 \mathrm{mmol} / \mathrm{l})$ concentrations in the icodextrin group [32]. The mean serum maltose level increased from a pre-dialysis value of $0.04 \mathrm{~g} / \mathrm{l}$ to a steady- 
state level of $1.20 \mathrm{~g} / \mathrm{l}$ within 2 weeks and remained stable throughout the study, which supports the mechanism described above.

Wolfson et al. [41] also observed that serum sodium and chloride decreased slightly from baseline in the icodextrin group $(-2.8$ and $-1.1 \mathrm{mmol} / \mathrm{l}$ respectively, $\mathrm{p}<$ 0.001 ) but were unchanged or slightly increased in the dextrose group.

Although statistically significant, the small reduction in serum sodium $(\sim 2 \mathrm{mmol} / \mathrm{l})$ consistently observed in multiple trials is likely not clinically relevant. One highrisk group may be poorly controlled diabetic patients started on icodextrin, which is paradoxically the patient population most likely to benefit from glucose-sparing solutions like icodextrin. Gradden et al. [43] reported neurological complications secondary to hyponatremia in 2 diabetic patients using icodextrin. Both of these patients were non-adherent to free water restriction and presented with severe hyperglycemia (glucose $>50 \mathrm{mmol} / \mathrm{l}$ ) and hyponatremia $(\mathrm{Na}<121 \mathrm{mmol} / \mathrm{l})$. The authors suspect that the combined osmotic effect of icodextrin metabolites and relative hyperglycemia may have contributed to the greater drop in plasma sodium in these patients.

Therefore, in rare cases, icodextrin may contribute to clinically relevant symptoms if the hyponatremia is compounded by other factors. Otherwise, the greatest risk to PD patients from icodextrin-induced hyponatremia would be iatrogenic. PD patients using icodextrin should not be free water restricted for mild hyponatremia, which may cause unnecessary patient discomfort and distress simply to resolve a laboratory abnormality that is unlikely to cause serious clinical sequelae in the absence of other contributing factors.

\section{Idiopathic Side Effects and Considerations}

\section{Rash}

The purported mechanism stems from the similar structure of icodextrin to another glucose polymer, dextran. The difference between dextrin and dextran is the polymer link ( $\alpha 1,4$ and $\alpha 1,6$ Iinkages respectively). Dextran is used as a plasma expander or as an anticoagulant, and it is well known to cause allergic-type reactions [44]. Although the epitope for the dextran allergic reaction has not been identified, there have been studies that have confirmed the immunogenicity of dextrans and the formation of immunocomplexes with skin localization [45]. It is plausible that either the same or a similar epitope may also be responsible for the hypersensitivity reaction seen with icodextrin. In addition, icodextrin is derived from cornstarch, and so it should not be used in patients with a documented corn allergy.

The skin rash associated with icodextrin often is described as a mild or moderate psoriasiform macular rash that includes peeling of the skin over the palms of the hands and soles of the feet. However, generalized and pustular rashes have also been reported $[45,46]$. When a rash occurs, it generally develops early in therapy, is selflimited, and resolves without consequences after discontinuation of icodextrin.

A single-center retrospective study in the United Kingdom reviewed their initial experience with icodextrin from October 1998/1999 [46]. At that stage, 102 patients had been exposed to icodextrin, which was maintained for 6 months or more in 80 patients. The prevalence of skin reactions in their center was $15 \%$ [46]. Reported skin reactions in the patients exposed to icodextrin were of two types - blistering and exfoliative. Acute blistering reactions occurred on sun-exposed areas (hands, face, and neck) and tended to occur at 3 and 6 months after commencement of icodextrin. Patients responded to icodextrin withdrawal, taking approximately 6-7 weeks to resolve completely. Skin biopsy samples showed non-specific inflammatory changes. Exfoliative reactions were acute, generalized, pruritic, rapidly worsening, and started soon after first icodextrin exposure (under 5 days in all patients). All responded to prompt withdrawal of icodextrin, with symptoms improving in all cases within $48 \mathrm{~h}$ of icodextrin discontinuation.

Baxter Healthcare also maintains a continuous surveillance program through a global pharmacovigilance system [47]. By the end of August 1999, data from this database revealed an incidence of 108 skin reactions in over 4,000 patients, resulting in a rate of about $2.5 \%$. In most cases, the symptoms were mild and over $50 \%$ of the 108 reported cases were maintained on icodextrin therapy.

The major limitation of case series and retrospective data is the lack of a pre-specified control group, and so the randomized controlled trial data is particularly important to review. In their 2-week study, Finkelstein et al. [20] found that rash was the only adverse event that occurred significantly more often in the icodextrin group $(17 \%)$ than the control group $(0 \%, p<0.006)$. Six of the 8 patients with rash completed the study, and maculopapular rash was the most common rash described, occurring in 3 of 8 icodextrin patients.

Wolfson et al. [41] found there was no statistical difference between the icodextrin and dextrose groups in the 
composite outcome of rash, exfoliative dermatitis, or overall skin-related adverse events (icodextrin $44 \%$, dextrose $40.2 \%$ ) in their 52-week study. However, skin rash was reported in more patients in the icodextrin group (18.9\%) than in the dextrose group (11.6\%). Exfoliative dermatitis occurred in $2.3 \%$ of the patients using icodextrin versus $0.9 \%$ of patients using dextrose. Moreover, 5 patients in the icodextrin group withdrew from the study because of adverse events related to the skin, whereas no patients in the dextrose group withdrew because of skin-related adverse events $(2.9 \%$ vs. $0 \%, \mathrm{p}<0.071)$. The most common icodextrin rash in this trial was mild to moderate in severity, self-limited, and without serious adverse events.

More recently, the IMPENDIA-EDEN trial found that a skin rash developed in 12 patients $(1 \%)$ in the icodextrin group compared to 6 patients $(0.5 \%)$ in the dextrose group [10]. Similar rates were reported by more recent, but small clinical trials $[22,48]$. One explanation for these lower rates are improvements in the quality of icodextrin preparation, especially since peptidoglycan were removed in 2007.

Therefore, the current evidence suggests that icodextrin skin reactions limited to the palms and soles do not necessitate icodextrin withdrawal, but careful medical attention to monitor for progression is needed. When a rash does occur, it generally develops early in therapy. Rashes have been reported even after prolonged icodextrin exposure; however, the high-risk period appears to be the first 14 days of icodextrin initiation, when heightened surveillance for rash-onset would be indicated. Immediate icodextrin withdrawal should be considered when diffuse or pustular rash develops. With a pustular rash, we consider rechallenging patients with icodextrin after 6 months, since the source of the immunogenic response may have waned. Patients are often unwilling to try icodextrin for a second time though, and risk suffering another rash. Icodextrin rashes of all types should be recorded and reported to enable post-marketing surveillance.

\section{Sterile Peritonitis}

In 2001/2002, an outbreak of culture-negative peritonitis was reported with a prevalence of up to $8.7 \%[49,50]$. The first cases were reported in 1999, and a number of cases of aseptic peritonitis occurred in Europe in early 2002 [49]. The prevalence is probably underestimated because of the absence of clinical symptoms and the nondetection of cloudy dialysates in some patients.

These reactions are characterized by mild abdominal discomfort, cloudy effluent, dialysate hypercellularity

Considerations When Prescribing

Icodextrin
(WBC $>100 / \mathrm{mm}^{3}$ ) with a predominance of macrophages and absence of neutrophils, sterile cultures, and few systemic symptoms. Delay between the initiation of icodextrin and sterile peritonitis onset varies in the literature, ranging from immediately to over 8 months $[51,52]$. Some patients on CAPD may report that the dialysate progressively clears during the day when dextrose solutions are usually used [50]. On APD, the presence of cloudy dialysate is less easily detected, which might explain the absence of description of these reactions in APD patients, though it may be detected during the initial drain [50].

Toure et al. [49] performed a case-control study to examine the clinical and biologic features of 5 patients with icodextrin-induced peritonitis between January and June 2002. Icodextrin was incriminated in all 5 patients because recovery of peritonitis was obtained $48 \mathrm{~h}$ after discontinuation of icodextrin and recurrence occurred on re-exposure. In June 2002, Baxter Healthcare reported that icodextrin solution used during this time period contained abnormal amounts of peptidoglycan [53]. This peptidoglycan was issued from Bacillus acidocaldarius, a bacteria found to contaminate the starch used in the production of icodextrin [49].

According to Baxter Healthcare's pharmacovigilance program, sterile peritonitis secondary to icodextrin was reported in less than $1 \%$ of patients before January 2001, with prevalence reaching more than $10 \%$ during the first 6 months of 2002 [49]. These reports originated from a wide selection of countries, including the United Kingdom, Spain, The Netherlands, Denmark, Sweden, Belgium, Switzerland, Italy, Germany, and France. To our knowledge, there were no reports from Asia, North America, and Australia which may relate to different sources of icodextrin [53]. Recalling contaminated batches by Baxter Healthcare allowed the prevalence of sterile peritonitis to decrease back to $1 \%$ [49].

However, recurrence of sterile peritonitis on rechallenging with new unaffected lots of icodextrin has been reported [54]. One explanation may be that the lots of icodextrin used for rechallenge still contained a very low amount of peptidoglycan. Since June 2002, icodextrin batches are guaranteed to contain $<7.4 \mathrm{ng} / \mathrm{ml}$ of peptidoglycan, but they are not guaranteed to be free of peptidoglycan [49]. It is therefore possible that a very low concentration of peptidoglycan still may be able induce an immunologic response in sensitized patients. Nonetheless, the improved preparation of icodextrin has had an effect on lowering the rates of sterile peritonitis.

It is important for healthcare providers to recognize icodextrin-related sterile peritonitis in order to avoid un- 
necessary ongoing antibiotic prescription or even PD catheter removal. This can be difficult. Our local practice is to delay icodextrin in incident PD patients for 4-6 weeks so that sterile peritonitis is not confused with eosinophilic peritonitis, which occurs early after PD initiation regardless of PD solution. If sterile peritonitis with icodextrin is diagnosed, the severity of the reaction will help dictate whether icodextrin cessation is needed. For mild reactions, icodextrin could be continued, with the hope of a progressive reduction in symptoms. Withdrawal of icodextrin is usually necessary in cases of severe reactions. The dialysate usually clears within $24-48 \mathrm{~h}$ of icodextrin cessation [55]. If the PD effluent becomes clear, then icodextrin should not be reintroduced unless under close supervision. If the cloudy fluid recurs with icodextrin rechallenge, then the patient should not be prescribed icodextrin in the future. In severe cases of sterile peritonitis, a rechallenge of icodextrin could be hazardous and should not be attempted [55]. However, even if clinically tolerable, the long-term consequences for the peritoneal membrane of recurrent chemical peritonitis and lowgrade mononuclear inflammation remain unknown. As above for rash, sterile peritonitis with icodextirn should be recorded and reported to enable post-marketing surveillance.

\section{Antibiotic Compatibility}

In the 2000 update to the International Society of Peritoneal Dialysis (ISPD) guidelines, a combination of intraperitoneal cefazolin and ceftazidime was recommended for initial empiric treatment of peritonitis [56]. The 2010 update states that Gram-positive organisms may be covered by vancomycin or a cephalosporin and Gram-negative organisms by a third-generation cephalosporin or aminoglycoside [57]. The ISPD guidelines also recommend center-specific protocols based upon local microbial patterns and sensitivities. These guidelines do not mention the type of peritoneal fluid that is compatible for the administration of intraperitoneal antibiotics.

This choice could be important. The ISPD guidelines recommend that IP antibiotics be allowed to dwell for at least $6 \mathrm{~h}$ [57], which may predispose patients to UF failure if they convert to rapid transporters due to increased membrane inflammation. As a result, icodextrin may be an ideal fluid for antibiotic administration to compensate for UF failure. It is important to be certain that various antimicrobials are both stable and effective if they are used in icodextrin solution to treat bacterial peritonitis. Moreover, the shelf life of PD fluids should be studied at room, refrigeration, and body temperatures. Bags are
Table 2. Antibiotic stability in icodextrin

\begin{tabular}{|c|c|c|c|}
\hline Drug & $\begin{array}{l}\text { Concentration, } \\
\mathrm{mg} / \mathrm{l}\end{array}$ & $\begin{array}{l}\text { Drug stability in } \\
\text { PVC containers }\end{array}$ & $\begin{array}{l}\text { Drug stability } \\
\text { in polyolefin } \\
\text { containers }\end{array}$ \\
\hline $\begin{array}{l}\text { Vancomycin } \\
{[58,59]}\end{array}$ & 1,000 & $\begin{array}{l}7 \text { days at } 4^{\circ} \mathrm{C} \\
7 \text { days at } 24^{\circ} \mathrm{C} \\
1 \text { day at } 37^{\circ} \mathrm{C}\end{array}$ & 1 day at $25^{\circ} \mathrm{C}$ \\
\hline $\begin{array}{l}\text { Cefazolin } \\
{[58,61]}\end{array}$ & $\begin{array}{l}500^{\mathrm{a}} \\
750^{\mathrm{b}}\end{array}$ & $\begin{array}{l}30 \text { days at } 4^{\circ} \mathrm{C} \\
7 \text { days at } 25^{\circ} \mathrm{C} \\
1 \text { day at } 38^{\circ} \mathrm{C}\end{array}$ & 1 day at $25^{\circ} \mathrm{C}$ \\
\hline $\begin{array}{l}\text { Ceftazidime } \\
{[60]}\end{array}$ & 500 & $\begin{array}{l}7 \text { days at } 4^{\circ} \mathrm{C} \\
2 \text { days at } 25^{\circ} \mathrm{C} \\
8 \mathrm{~h} \text { at } 37^{\circ} \mathrm{C}\end{array}$ & \\
\hline Cefepime [62] & 500 & $\begin{array}{l}7 \text { days at } 4^{\circ} \mathrm{C} \\
2 \text { days at } 20^{\circ} \mathrm{C} \\
4 \mathrm{~h} \text { at } 37^{\circ} \mathrm{C}\end{array}$ & \\
\hline $\begin{array}{l}\text { Tobramycin } \\
{[58,60]}\end{array}$ & $\begin{array}{l}40^{\mathrm{a}} \\
60^{\mathrm{b}}\end{array}$ & $\begin{array}{l}14 \text { days at } 4^{\circ} \mathrm{C} \\
7 \text { days at } 25^{\circ} \mathrm{C} \\
1 \text { day at } 37^{\circ} \mathrm{C}\end{array}$ & 1 day at $25^{\circ} \mathrm{C}$ \\
\hline Gentamicin [58] & 60 & & 1 day at $25^{\circ} \mathrm{C}$ \\
\hline Netilmicin [58] & 60 & & 1 day at $25^{\circ} \mathrm{C}$ \\
\hline
\end{tabular}

commonly stored at room temperature for practical reasons, but refrigeration may provide a longer shelf life for the solution. Determination at body temperature is necessary because patients may pre-warm PD solutions before each exchange in order to increase comfort.

Table 2 summarizes the antimicrobial stability data of icodextrin in polyolefin and polyvinyl chloride (PVC) containers [58-62]. Stability data for solution in nonPVC containers may not be applicable to containers made of PVC, since some medications may adsorb to the PVC container material [58]. The dosage of each antibiotic in the above studies followed the recommended treatment dose [56]. Drugs were considered stable if their concentration exceeded $90 \%$ of the original, which is a percentage used in previous studies.

It is important to note a few of the major limitations to all these studies. First, they only address the chemical and physical stability of antibiotics in icodextrin solution, not the antimicrobial stability. Second, there is little data on combining antibiotics in icodextrin solution. We are aware of two such studies. One showed that combining vancomycin and gentamicin in an icodextrin-based solution did not result in any loss of activity at room temper- 


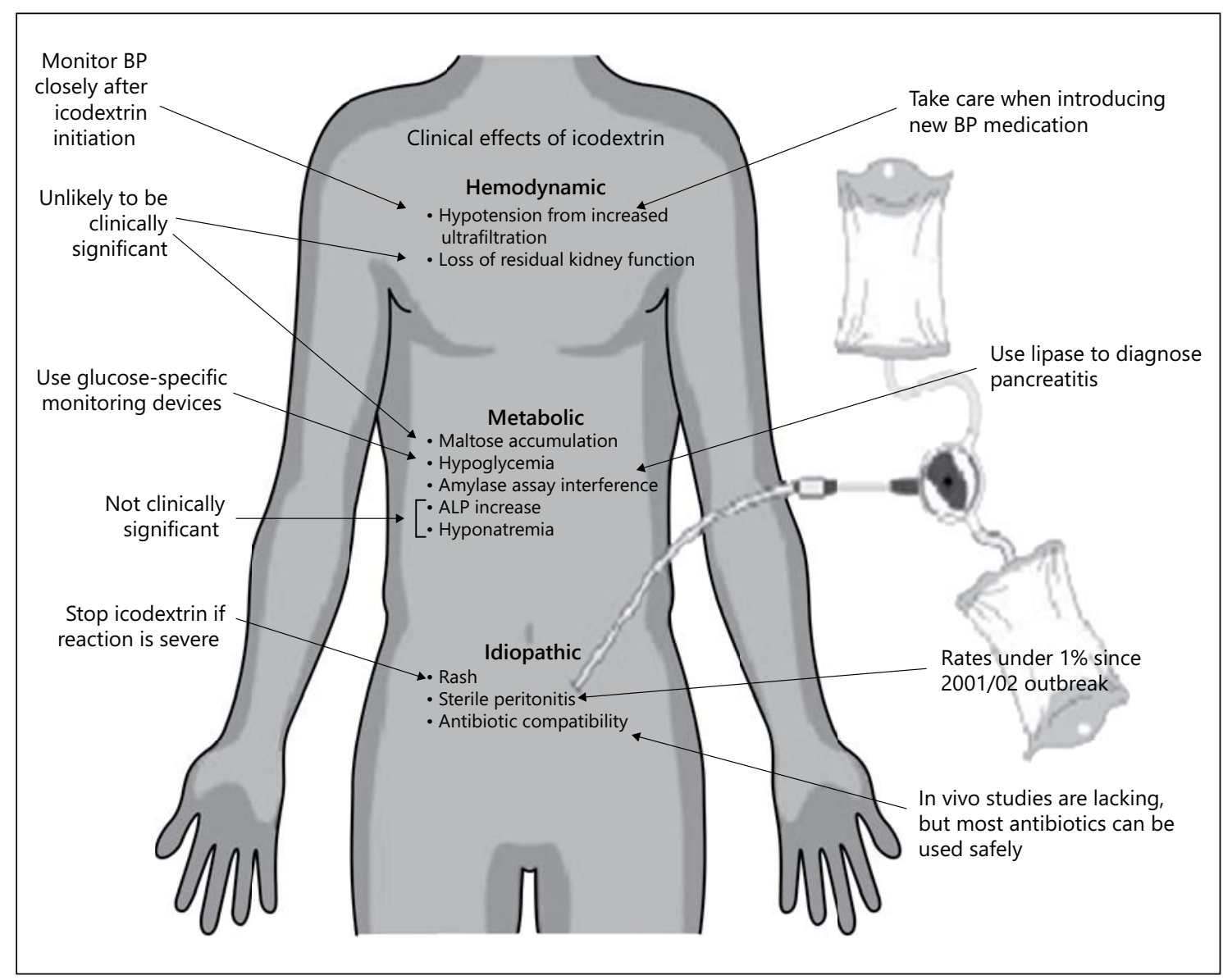

Fig. 3. Strategies to decrease adverse events from icodextrin.

ature in $48 \mathrm{~h}$ [63]. The second, more recent study, demonstrated the stability of cefazolin and ceftazidime in icodextrin at $4^{\circ} \mathrm{C}(168 \mathrm{~h}), 25^{\circ} \mathrm{C}(24 \mathrm{~h})$, and $37^{\circ} \mathrm{C}(24 \mathrm{~h})$ [64]. Third, there are only two studies to our knowledge that evaluated the biocompatibility of icodextrin, antibiotics, and heparin. They demonstrated the stability of cefazolin and vancomycin in an icodextrin-heparin solution for $48 \mathrm{~h}[61,63]$. In the absence of more definitive evidence, it would appear reasonable to mix icodextrin only with antibiotics and heparin that are known to also be stable in dextrose solutions.

\section{Conclusion}

Icodextrin use is increasing globally, in large part due to its ability to enhance UF and minimize glucose exposure. Therefore, nephrologists' experience with its administration must also continue to evolve. Current evi- dence supports several hemodynamic and metabolic consequences of icodextrin use, which all practitioners that care for PD patients should be aware (fig. 3).

Some of these concerns are predictable and secondary to the augmented UF provided by icodextrin. For example, when starting icodextrin, care should be taken to closely monitor blood pressure. It is possible that the enhanced UF from icodextrin could lead to orthostatic hypotension and syncope if blood pressure medications are not adjusted accordingly.

Other icodextrin concerns are related to its chemical structure, and its interference with biochemical assays. If these effects are not appreciated, PD patients could be erroneously diagnosed with hyperglycemia and treated with insulin unnecessarily. Severe hypoglycemia and coma have been reported, which are an obvious threat to patient safety.

Icodextrin also has some idiopathic adverse effects. The most common of these side effects is a macular rash, 
which can be quite distressing to patients. If not properly recognized and managed, this could lead to premature discontinuation of PD.

Lastly, even though most antibiotics are stable in icodextrin at all temperatures, there is little data available on the stability of antibiotic combinations. Data is also needed on antibiotic stability when heparin is added to icodextrin.

As with any therapy, some side effects do not emerge in initial studies, but rather require years of post-marketing surveillance in order to be identified. Therefore, clinicians using icodextrin should disseminate knowledge as experience with this agent evolves. In this way, healthcare providers will be able to confidently prescribe icodextrin to the benefit of PD patients, while minimizing and avoiding any undue risks.

\section{Conflicts of Interest}

JP has received speaking honoraria from Baxter Healthcare, Amgen Canada, and Davita Healthcare Partners. JP has also received consulting fees from Baxter Healthcare, Shire, Takeda, Janssen Inc. as well as research support from Baxter Healthcare.

\section{References}

1 Mistry CD: The beginning of icodextrin. Perit Dial Int 2011;31(suppl 2):S49-S52.

$>2$ Blake PG: Icodextrin: fifteen years and counting. Introduction. Perit Dial Int 2009;29:367369.

3 Moberly JB, Mujais S, Gehr T, Hamburger R, Sprague S, Kucharski A, Reynolds R, Ogrinc F, Martis L, Wolfson M: Pharmacokinetics of icodextrin in peritoneal dialysis patients. Kidney Int Suppl 2002;81:S23-S33.

4 Garcia-Lopez E, Lindholm B: Icodextrin metabolites in peritoneal dialysis. Perit Dial Int 2009;29:370-376.

5 Raja RM, Cantor RE, Boreyko C, Bushehri H, Kramer MS, Rosenbaum JL: Sodium transport during ultrafiltration peritoneal dialysis. Trans Am Soc Artif Intern Organs 1972;18: 429-435.

6 Rippe B, Levin L: Computer simulations of ultrafiltration profiles for an icodextrin-based peritoneal fluid in CAPD. Kidney Int 2000;57: 2546-2556.

7 Cho Y, Johnson DW, Badve S, Craig JC, Strippoli GF, Wiggins KJ: Impact of icodextrin on clinical outcomes in peritoneal dialysis: a systematic review of randomized controlled trials. Nephrol Dial Transplant 2013;28:18991907.

8 Qi H, Xu C, Yan H, Ma J: Comparison of icodextrin and glucose solutions for long dwell exchange in peritoneal dialysis: a meta-analysis of randomized controlled trials. Perit Dial Int 2011;31:179-188.

9 Woodrow G, Oldroyd B, Stables G, Gibson J, Turney JH, Brownjohn AM: Effects of icodextrin in automated peritoneal dialysis on blood pressure and bioelectrical impedance analysis. Nephrol Dial Transplant 2000;15:862866.

10 Li PK, Culleton BF, Ariza A, Do JY, Johnson DW, Sanabria M, Shockley TR, Story K, Vatazin A, Verrelli M, Yu AW, Bargman JM: Randomized, controlled trial of glucose-sparing peritoneal dialysis in diabetic patients. J Am Soc Nephrol 2013;24:1889-1900.

-11 Bredie SJ, Bosch FH, Demacker PN, Stalenhoef AF, van Leusen R: Effects of peritoneal dialysis with an overnight icodextrin dwell on parameters of glucose and lipid metabolism. Perit Dial Int 2001;21:275-281.

12 Paniagua R, Orihuela O, Ventura MD, AvilaDiaz M, Cisneros A, Vicente-Martinez M, Furlong MD, Garcia-Gonzalez Z, Villanueva D, Prado-Uribe MD, Alcantara G, Amato D: Echocardiographic, electrocardiographic and blood pressure changes induced by icodextrin solution in diabetic patients on peritoneal dialysis. Kidney Int Suppl 2008; 108:S125-S130.

13 Konings CJ, Kooman JP, Schonck M, Gladziwa U, Wirtz J, van den Wall Bake AW, Gerlag PG, Hoorntje SJ, Wolters J, van der Sande FM, Leunissen KM: Effect of icodextrin on volume status, blood pressure and echocardiographic parameters: A randomized study. Kidney Int 2003;63:1556-1563.

14 Hiramatsu T, Hayasaki T, Hobo A, Furuta S, Kabu K, Tonozuka Y, Iida Y: Icodextrin eliminates phosphate and ameliorates cardiac hypertrophy and valvular calcification in patients with end-stage renal disease and diabetes mellitus undergoing peritoneal dialysis. Adv Perit Dial 2013;29:9-13.

15 Lin W, Chen YC, Wu MS, Hsu HJ, Sun CY, Lin YK, Wu IW: Icodextrin dialysate improves nutritional and inflammatory profiles in peritoneal dialysis patients. Ren Fail 2009; 31:98-105.

16 Martikainen TA, Teppo AM, GronhagenRiska C, Ekstrand AV: Glucose-free dialysis solutions: inductors of inflammation or preservers of peritoneal membrane? Perit Dial Int 2005;25:453-460.

17 Moriishi M, Kawanishi H: Icodextrin and intraperitoneal inflammation. Perit Dial Int 2008;28(suppl 3):S96-S100.

18 Takatori Y, Akagi S, Sugiyama H, Inoue J, Kojo S, Morinaga H, Nakao K, Wada J, Makino $\mathrm{H}$ : Icodextrin increases technique survival rate in peritoneal dialysis patients with diabetic nephropathy by improving body fluid management: a randomized controlled trial. Clin J Am Soc Nephrol 2011;6:13371344.
19 Han SH, Ahn SV, Yun JY, Tranaeus A, Han DS: Effects of icodextrin on patient survival and technique success in patients undergoing peritoneal dialysis. Nephrol Dial Transplant 2012;27:2044-2050.

20 Finkelstein F, Healy H, Abu-Alfa A, Ahmad S, Brown F, Gehr T, Nash K, Sorkin M, Mujais S: Superiority of icodextrin compared with $4.25 \%$ dextrose for peritoneal ultrafiltration. J Am Soc Nephrol 2005; 16:546554.

21 Davies SJ, Woodrow G, Donovan K, Plum J, Williams P, Johansson AC, Bosselmann HP, Heimbürger $O$, Simonsen $O$, Davenport A, Tranaeus A, Divino Filho JC: Icodextrin improves the fluid status of peritoneal dialysis patients: results of a double-blind randomized controlled trial. J Am Soc Nephrol 2003; 14:2338-2344.

22 Paniagua R, Ventura MD, Avila-Diaz M, Cisneros A, Vicente-Martinez M, Furlong MD, Garcia-Gonzalez Z, Villanueva D, Orihuela O, Prado-Uribe MD, Alcantara G, Amato D: Icodextrin improves metabolic and fluid management in high and high-average transport diabetic patients. Perit Dial Int 2009;29: 422-432.

23 Mujais S, Nolph K, Gokal R, Blake P, Burkart J, Coles G, Kawaguchi Y, Kawanishi H, Korbet S, Krediet R, Lindholm B, Oreopoulos D, Rippe B, Selgas R: Evaluation and management of ultrafiltration problems in peritoneal dialysis. International Society for Peritoneal Dialysis Ad Hoc Committee on Ultrafiltration Management in Peritoneal Dialysis. Perit Dial Int 2000;20(suppl 4):S5S21.

24 Jones CH, Wells L, Stoves J, Farquhar F, Woodrow G: Can a reduction in extracellular fluid volume result in increased serum albumin in peritoneal dialysis patients? Am J Kidney Dis 2002;39:872-875.

25 Günal AI, Duman S, Özkahya M, Töz H, Asçi G, Akçiçek F, Basçi A: Strict volume control normalizes hypertension in peritoneal dialysis patients. Am J Kidney Dis 2001;37:588593. 
-26 Rodriguez-Carmona A, Perez Fontan M, Garcia Lopez E, Garcia Falcon T, Diaz Cambre H: Use of icodextrin during nocturnal automated peritoneal dialysis allows sustained ultrafiltration while reducing the peritoneal glucose load: a randomized crossover study. Perit Dial Int 2007;27:260-266.

27 Weser E, Sleisenger MH: Metabolism of circulating disaccharides in man and the rat. J Clin Invest 1967;46:499-505.

-28 Bergonzi G, Paties C, Vassallo G, Zangrandi A, Poisetti PG, Ballocchi S, Fontana F, Scarpioni L: Dextran deposits in tissues of patients undergoing haemodialysis. Nephrol Dial Transplant 1990;5:54-58.

-29 Thompson WL, Fukushima T, Rutherford $\mathrm{RB}$, Walton RP: Intravascular persistence, tissue storage, and excretion of hydroxyethyl starch. Surg Gynecol Obstet 1970;131:965972.

-30 Gamklou R, Schersten T: Activity of $\alpha$-amylase and a1,4-glucosidase in human liver tissue. Scand J Clin Lab Invest 1972;30:201-207.

-31 Garcia-Lopez E, Anderstam B, Heimburger O, Amici G, Werynski A, Lindholm B: Determination of high and low molecular weight molecules of icodextrin in plasma and dialysate, using gel filtration chromatography, in peritoneal dialysis patients. Perit Dial Int 2005;25:181-191.

-32 Mistry CD, Gokal R, Peers E: A randomized multicenter clinical trial comparing isosmolar icodextrin with hyperosmolar glucose solutions in CAPD. MIDAS Study Group. Multicenter investigation of icodextrin in ambulatory peritoneal dialysis. Kidney Int 1994;46: 496-503.

33 Davies DS: Kinetics of icodextrin. Perit Dial Int 1994;14:S45-S50.

- 34 Dousdampanis P, Trigka K, Chu M, Khan S, Venturoli D, Oreopoulos DG, Bargman JM: Two icodextrin exchanges per day in peritoneal dialysis patients with ultrafiltration failure: one center's experience and review of the literature. Int Urol Nephrol 2011;43:203209.

- 35 Freida P, Issad B, Dratwa M, Lobbedez T, Wu L, Leypoldt JK, Divino-Filho JC: A combined crystalloid and colloid PD solution as a glucose-sparing strategy for volume control in high-transport APD patients: a prospective multicenter study. Perit Dial Int 2009;29:433442.

-36 Gokal R, Moberly J, Lindholm B, Mujais S: Metabolic and laboratory effects of icodextrin. Kidney Int Suppl 2002;81:S62-S71.

-37 Tonyushkina K, Nichols JH: Glucose meters: a review of technical challenges to obtaining accurate results. J Diabetes Sci Technol 2009; 3:971-980.
Firanek CA, Jacob DT, Sloand JA: Avoidable iatrogenic hypoglycemia in patients on peritoneal dialysis: the risks of nonspecific glucosemonitoring devices and drug-device interaction. J Patient Saf 2013, Epub ahead of print.

39 Sloand JA: Dialysis patient safety: safeguards to prevent iatrogenic hypoglycemia in patients receiving icodextrin. Am J Kidney Dis 2012;60:514-516.

40 Schoenicke G, Grabensee B, Plum J: Dialysis with icodextrin interferes with measurement of serum $\alpha$-amylase activity. Nephrol Dial Transplant 2002;17:1988-1992.

41 Wolfson M, Piraino B, Hamburger RJ, Morton AR: A randomized controlled trial to evaluate the efficacy and safety of icodextrin in peritoneal dialysis. Am J Kidney Dis 2002;40: 1055-1065.

42 Plum J, Gentile S, Verger C, Brunkhorst R, Bahner U, Faller B, Peeters J, Freida P, Struijk DG, Krediet RT, Grabensee B, Tranaeus A, Filho JC: Efficacy and safety of a 7.5\% icodextrin peritoneal dialysis solution in patients treated with automated peritoneal dialysis. Am J Kidney Dis 2002;39:862-871.

43 Gradden CW, Ahmad R, Bell GM: Peritoneal dialysis: new developments and new problems. Diabet Med 2001;18:360-363.

44 Berg EM, Fasting S, Sellevold OF: Serious complications with dextran-70 despite hapten prophylaxis. Is it best avoided prior to delivery? Anaesthesia 1991;46:1033-1035.

45 Valance A, Lebrun-Vignes B, Descamps V, Queffeulou G, Crickx B: Icodextrin cutaneous hypersensitivity: report of 3 psoriasiform cases. Arch Dermatol 2001;137:309-310.

46 Goldsmith D, Jayawardene S, Sabharwal N, Cooney K: Allergic reactions to the polymeric glucose-based peritoneal dialysis fluid icodextrin in patients with renal failure. Lancet 2000;355:897.

47 Filho JCD: Allergic reactions to icodextrin in patients with renal failure. Lancet 2000;355: 1364-1365.

48 Lin A, Qian J, Li X, Yu X, Liu W, Sun Y, Chen N, Mei C: Randomized controlled trial of icodextrin versus glucose containing peritoneal dialysis fluid. Clin J Am Soc Nephrol 2009;4: 1799-1804.

49 Toure F, Lavaud S, Mohajer M, Lavaud F, Canivet E, Nguyen P, Chanard J, Rieu P: Icodextrin-induced peritonitis: study of five cases and comparison with bacterial peritonitis. Kidney Int 2004;65:654-660.

50 Tintillier M, Pochet JM, Christophe JL, Scheiff JM, Goffin E: Transient sterile chemical peritonitis with icodextrin: clinical presentation, prevalence, and literature review. Perit Dial Int 2002;22:534-537.

51 Del Rosso G, Di Liberato L, Perilli A, Cappelli P, Bonomini M: A new form of acute adverse reaction to icodextrin in a peritoneal dialysis patient. Nephrol Dial Transplant 2000; 15:927-928.
52 Pinerolo MC, Porri MT, D’Amico G: Recurrent sterile peritonitis at onset of treatment with icodextrin solution. Perit Dial Int 1999; 19:491-492.

53 Dombros N, Dratwa M, Feriani M, Gokal R, Heimburger O, Krediet R, Plum J, Rodrigues A, Selgas R, Struijk D, Verger C: European best practice guidelines for peritoneal dialysis. Five peritoneal dialysis solutions. Nephrol Dial Transplant 2005;20(suppl 9):IX16IX20.

54 Basile C, De Padova F, Montanaro A, Giordano R: The impact of relapsing sterile icodextrin-associated peritonitis on peritoneal dialysis outcome. J Nephrol 2003;16:384-386.

55 Gokal R: Icodextrin-associated sterile peritonitis. Perit Dial Int 2002;22:445-448.

56 Keane WF, Bailie GR, Boeschoten E, Gokal R, Golper TA, Holmes CJ, Kawaguchi Y, Piraino B, Riella M, Vas S; International Society for Peritoneal Dialysis: Adult peritoneal dialysisrelated peritonitis treatment recommendations: 2000 update. Perit Dial Int 2000;20: 396-411.

57 Li PK, Szeto CC, Piraino B, Bernardini J, Figueiredo AE, Gupta A, Johnson DW, Kuijper EJ, Lye WC, Salzer W, Schaefer F, Struijk DG; International Society for Peritoneal Dialysis: Peritoneal dialysis-related infections recommendations: 2010 update. Perit Dial Int 2010;30:393-423.

58 Voges M, Faict D, Lechien G, Taminne M: Stability of drug additives in peritoneal dialysis solutions in a new container. Perit Dial Int 2004;24:590-595.

59 Nornoo AO, Elwell RJ: Stability of vancomycin in icodextrin peritoneal dialysis solution. Ann Pharmacother 2006;40:1950-1954.

60 Pallotta KE, Elwell RJ, Nornoo AO, Manley $\mathrm{HJ}$ : Stability of tobramycin and ceftazidime in icodextrin peritoneal dialysis solution. Perit Dial Int 2009;29:52-57.

61 Robinson RF, Morosco RS, Smith CV, Mahan JD: Stability of cefazolin sodium in four heparinized and non-heparinized dialysate solutions at 38 degrees celsius. Perit Dial Int 2006 26:593-597.

62 Elwell RJ, Volino LR, Frye RF: Stability of cefepime in icodextrin peritoneal dialysis solution. Ann Pharmacother 2004;38:20412044.

63 Choo CG: Compatibility of $7.5 \%$ polyglucose peritoneal dialysis solution with gentamicin, vancomycin, heparin, and insulin. Perit Dial Int 1997;19:S94.

64 Patel RP, Shastri MD, Bakkari M, Wanandy T, Jose MD: Stability of the combination of ceftazidime and cephazolin in icodextrin or $\mathrm{pH}$ neutral peritoneal dialysis solution. Perit Dial Int 2014;34:212-218.
Considerations When Prescribing Icodextrin
Am J Nephrol 2014;39:515-527 DOI: $10.1159 / 000363417$ 